\title{
Teachers' Moral Evaluation of Students in an Inclusive Secondary School: A Study of Minority Students' Behaviour and School Performance
}

\author{
By Mohammed-Awal Alhassan*
}

\begin{abstract}
This study aims to analyze the issue of morality in a teaching and learning set up. After discussion and answering the question "Is it ever the case that teachers hold students morally blameworthy or praiseworthy for factors that are known to be beyond their control?" the study concludes that teachers hold students to be morally blameworthy or praiseworthy for factors that are beyond their control, because they do not fully comprehend their lack of control over their situation, which is still bad. The study also found that most teachers do not have a clear cross-cultural knowledge of minority students' background causing a moral judgement dilemma of students' behaviours and actions. A critical look at other variables that may affect students' learning is recommended by this study.
\end{abstract}

Keywords: minority students, blameworthy, praiseworthy, knowledge, moral judgement

\section{Introduction}

Research on morality and moral evaluation is not new, and has evolved around many fields including philosophy, social and developmental psychology. However, what is unique in the present study is its evaluation dilemma of cognitive, emotional and affective underpinnings of moral judgment with regards to the rightness or wrongness of students behaviours and teachers actions to correct them. The main research question "Are students held morally blameworthy or praiseworthy by their teachers for factors that are known to be beyond their control?" is sub-divided into two: (1) Are there universally accepted moral rules when teachers make moral judgments, on their students and (2) Are moral judgments situation specific out of a generality? We have tried to answer these two questions by talking to 52 students and 50 teachers while reviewing recent studies to find answers to these questions. The question about whether moral rules are universal and universally accepted seemed to be negative and not universally endorsed, also supported by literature. The question about moral judgment being innate is also proved by this study to be weak also based on the lack of a universal acceptance of moral judgment rules and modules.

A cross-cultural research has shown differences of moral rules with different cultures having different understanding and perceptions of what is morally good or bad. For example moral rules endorsed by Western cultures as acceptable may not be accepted norms in other non-Western cultures (Rai \& Fiske, 2011). Looking into the eyes of your teachers when talking to you is not accepted in some

\footnotetext{
"Lecturer, Nordre Follo Adult Institute, Norway.
} 
societies, while hitting or corporal punishment is accepted. Other moral domains, such as certain aspects of sexuality and sexual education and fairness are also highly variable (Rai \& Fiske, 2011; Sripada \& Stich, 2006). This means that the issue of moral rules and moral judgment vary considerably across cultures.

To address the second question this study has looked into evidence showing that moral cognitions are innate. According to Hauser (2006), there is no moral universality. Mikhail (2015) in a similar study found that the evidence about lack of universality already indicates that it is unlikely that specific moral rules are innate. It is not deniable that moral judgment and moral rules are likely to be components of a universal moral rules and judgment leading some researchers to propose that moral cognitions are nothing special, but part of the varieties of the contents of moral judgment. Bucciarelli, Khemlani, and Johnson-Laird (2008) noted that moral judgment should be culturally determined. With culturally diverse students in a multi-ethnic class, the question of whose and which cultural norms should determine the rule of order in the classroom is uncertain. Some researchers for example cling to the idea of moral reasoning based on modeling, with teachers showing examples. Gigerenzer (2010) argues that there is no special class of moral heuristics, rather a general social heuristics guide moral and non moral behavior.

\section{Theoretical Framework}

The theoretical basis of this study is Kohlberg's Rationalist Theory and Haidt's Social Intuitionist Model. The focus of these theories differ and views moral judgment differently. Kohlberg's (1981) views morality as a conscious moral reasoning where children and adults from many cultures move through a sequence of 3 levels and sub- stages. Level 1 is preconventional morality: a level characterized by fixed rules geared towards likelihood of punishment or rules abiding. Level 2 is conventional morality, this is reached when at an adult age. Here, the values of a group come into play, such as family, school and society. Children think of living up to the expectations of families, students think they should live up to the expectations of teachers and schools while citizens think they should live up to the expectations of the society they live in. According to Crain (1985), not everyone reaches level 3 which is the higher levels of reasoning as the justifications here transcend the level of norms and laws and focus on the legitimacy of the norms regulating society. What is more difficult in level 3 is that the violations of individual rights, is checked by law enforcing body. It is argued that Kohlberg did not believe in innate factors driving moral judgment but rather that our moral judgments are driven by a process of reasoning.

Haidt's Social Intuitionist Model is inspired by Hume. Haidt (2001) defines moral judgments as "good and bad". Thus the evaluation of good vs. bad of a particular behavior, actions or character of a person is done based on the cultural values set by the community or society where the individual is located. The concern of Haidt lies beyond the processes of individual reasoning. According to Haidt and Joseph (2007), individuals in any social set up influence one another. Haidt and Kesebir (2010) found that individuals are embedded in large social 
contexts in which they influence others, as they are influenced by others. Haidt (2001), criticizes Kohlberg's views and argues that moral intuitions are primarily based on unconscious intuitions, with justifications being post hoc rationalizations, setting the whole moral judgment issue in an institutional moral dilemmas.

Researchers such as Cushman, Young, and Hauser (2006) and Cushman, Young, and Greene (2010), posit that Kohlberg failed to consider dependency and variability of moral reasoning, and that a level and stages based moral judgment is a mere oversimplification as a result of different contextual factors involved in judgmental evaluations. The fact that individuals barely get beyond level 1 is culturally biased in favour of Western philosophical traditions and cultural norms, as against other ethnic group of individuals with non-Western cultural traditions.

It is seen from the on going discussion that the views of Haidt and Kolberg differ, nevertheless, Haidt's approach proved a valuable contrast to the rationalist approaches of Kohlberg (1981), in the sense that a lot of findings from different researchers have shown that moral judgments can be intuitive and automatic. All in all and in moral judgment individuals may lack clear initial intuitions and arrive at their judgments after careful deliberation ending up with differentiated dilemmas (Haidt \& Kesebir, 2010; Paxton \& Greene, 2010). The theories discussed above acknowledge both conscious reasoning and emotion- based intuitions (Harman, Mason, \& Sinnott-Armstrong, 2010; Hauser, 2006). Both play an important role in moral judgments of students behaviors in a multiethnic classrooms. However, they differ in what process they consider primary. Moral judgement should be based on concious reasoning (Cushman, Young, \& Hauser, 2006; Johnston, 2011; Cushman \& Young, 2011). In Figure 1 for example, it is easy for a teacher to loose control of his students.

Figure 1. The Dilemma of a Teacher

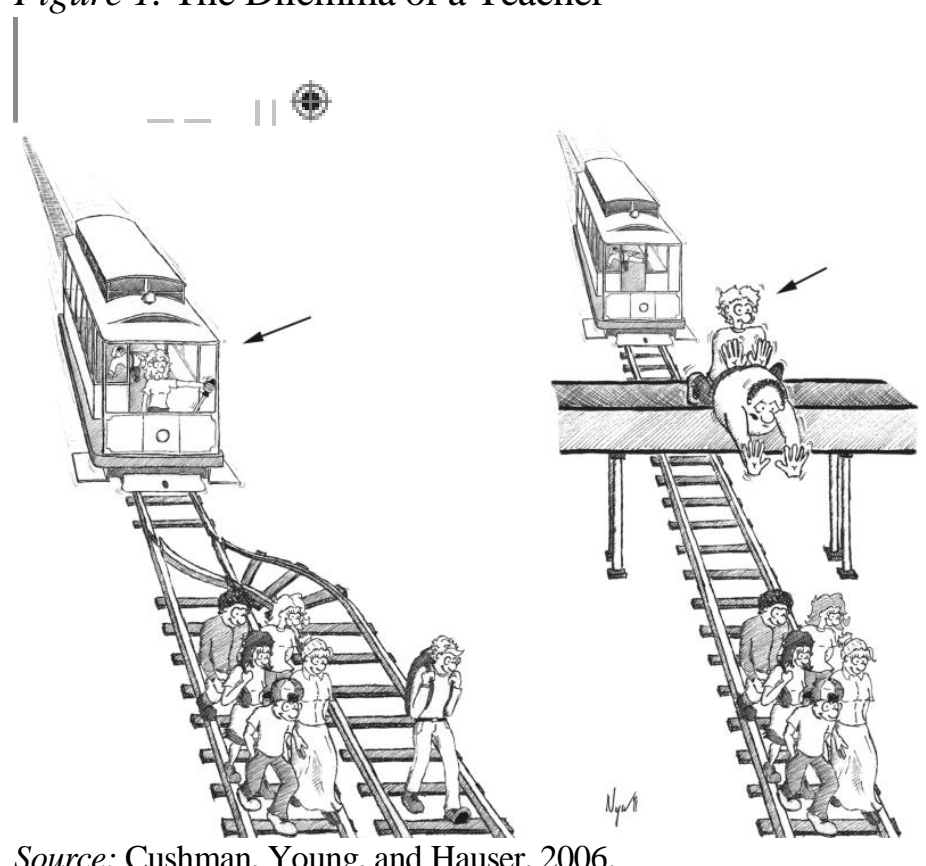


In Figure 1 there is a student $(\mathrm{X})$ standing on a bridge in an attempt to save five other students while a runaway train is also heading toward these five students in front of the bridge. Student $(\mathrm{X})$ has good intentions but is he right? In a study conducted to justify the intuition of student $(\mathrm{X}), 12 \%$ of the students interviewed said that student $(\mathrm{X})$ could stop the train, while $88 \%$ answered "no" The 12\% found it permissible for (X) to do what he did (Cushman, Young, \& Hauser 2006; Cushman, Young, \& Greene (2010). The authors interpret the effect as evidence for the unconscious use of the doctrine of double effect (DDE), which allows harming a person as a side effect, but not as a means of saving more people. The dilemma of the teacher here is quite evident. There is no doubt that student $(\mathrm{X})$ sat on the bridge with good intention while the teacher may see it as disobedient and bad behaviour. In a study by Awad et al. (2018) and Li et al. (2019), the legality of the teachers' dilemma was shown to affect moral judgements. However, their studies did not take into consideration the interplay between the train driver, the students and the teacher, something that future research should aim to elucidate. In a study of human behavior and assessment of a dangerous situation Li et al. (2019) found that personality characteristics predict the likelihood of drivers endangering themselves and others. In a similar study by Luzuriaga, Heras, and Kunze (2019), it was found that participants programming an automated vehicle were more readily to endanger car occupants to save pedestrians, than participants driving in a simulator. Although, the results of many moral judgement and moral action studies have been generally consistent, there are important distinctions between the approaches needing consideration before making strong conclusions. First, there is growing evidence of discrepancies between what people consider to be the right action in moral dilemmas and what they would actually do.

\section{Statement of the Problem}

Despite of the seemingly generous Norwegian Government's policy on asylum seekers, refugees and immigrants, there are still ill feelings amongst minority students of their teachers doing little to support their education. Many minority students and new arrivals in Norway take part in Introduction Programme the purpose of which is to enhance the opportunities that groups of new arrivals in Norway have to rapidly find work or enter education or training. Minority students who take part in this programme are entitled to an introduction grant, and when they are absent from school, they are punished in a form of money deductions from the grant they earn. Absence from schools of most of these students is a result of mental, psychological and other factors beyond the control of the students. There is also cultural element in people`s action and why they do what they do (Haidt, Koller, \& Dias, 1993). Teachers have mixed feelings for registering student's absence, but also see that absenteeism affect school performance of these students.

Establishing trust in minority students of teachers in terms of school absenteeism and school under-achievement among migrant students is a challenge, while minorities on the other hand blame their teachers of contributing to their 
school failure, in addition to students loosing income as a result of absenteeism. Researchers such as Nisreen and Saleh (2019) conclude that social background is the main reason why minority students underperform.

\section{Aim of the Study}

The aim of this study was to analyze the issue of morality in a school set up and to examine the trustworthiness or blame worthiness of teachers and students in teaching and learning situation.

\section{Research Questions}

1. Are students held morally blameworthy or praiseworthy by their teachers for factors that are known to be beyond their control?

2. Are there universally accepted moral rules when teachers make moral judgments, on their students?

3. Are moral judgments situation specific out of a generality?

\section{Methods}

A total of 52 students and 50 teachers from 4 schools from Østfold and Follo Districts of Norway participated in this study. The study was conducted by a combination of survey design and participant observation. The observational aspect of the study was designed to provide observation data from teachers' instructional behaviors and moral judgments of students socially and academically. Two observations were made, one in the classroom and another on the school playground to observe students behaviors when they are under a less control of their teachers.

\section{Participants}

The participants of the study consisted of 10th grade students and their teachers in 2019-2020 academic year. These students were minority adult students in their final 10th grade year in secondary school for adults, most of who are in the Norwegian Introduction Programme. The four schools from the two districts were selected by purposeful sampling. Purposeful sampling (Cohen \& Manion, 1994) was used to select the participants. Purposeful sampling was used as the purpose of the study was not that of a wide generalibility.

Participants were picked across 4 different schools within the Østfold and Follo Districts. Of the 50 teachers $62 \%$ (31) were female and $38 \%$ (19) were male while $50 \%$ (26) of the students were female and $50 \%$ (26) were male. 


\section{Instrumentation and Data Collection}

Using a quantitative research approach, the 50 secondary school teachers and 52 students were asked to complete a Moral Judgment Test (MJT) developed by Colby and Kohlberg (1987). The MJT required 30 minutes for implementation and completion of two dilemmas. The researcher introduced the test as two dilemmas one for the students and one for the teachers and requested each participant to consider the problem and consequently, provide their opinion in a Likert -scale type. Participants were to rate items from 1=Disagree, 2=Agree, 3=Strongly disagree, $4=$ Strongly agree. An open-ended question was provided to ask students about their opinion on the acceptance of moral rules and judgment globally.

Responses were marked with a penciled circle around the representative number. Upon completion participants were encouraged to check their answers before handing completed questionnaires back to the researcher. Questionnaires were completed anonymously.

The 52 students were also required to respond to Factors affecting their school performance and the 50 teachers who participated also responded to questionnaire requiring them to provide background information, and then rate their knowledge of other cultures and teaching practices to support minority students.

\section{Data Analysis}

The quantitative data were analysed using SPSS software. Descriptive statistics were calculated to answer the research questions. Frequencies, means and t-test were calculated as value judgment measurement of participants' responses.

\section{Results}

\section{Student Responses}

Moral Rules and Judgment. Under this theme, and as shown in Table 1 the objective of whether moral rules and judgment is internationally accepted was achieved, with as much as $96 \%$ of the students answering non- conventionality of moral rules and judgement.

Table 1. Acceptance of Moral Rules and Judgment Globally

\begin{tabular}{|l|c|c|}
\hline Response & Frequency & Percent \\
\hline No & 50 & 96 \\
\hline Yes & 2 & 4 \\
\hline Total & 52 & 100 \\
\hline
\end{tabular}

Blameworthiness and Praiseworthiness. When the 52 minority students were asked to rate their learning experiences and what prevents them from achieving, the analysis showed that many students blamed their teachers less than on issues outside the school and the school itself. Issues outside the school 
$(\mathrm{M}=7.2)$, and the School itself $(\mathrm{M}=6.3)$ as affecting their leaning more than Teachers $(\mathrm{M}=5.6)$ as shown in Table 2.

However, in comparing the mean scores of those with high rate of absenteeism from school and those without, the results showed that those who absented themselves from school had an overall higher mean $(M=6.6)$ on the perceived blameworthiness of low- academic performance compared to those who come to school regularly $(\mathrm{M}=4.4)$. The mean differences were statistically significant $(\mathrm{p}=0.00)$.

Table 2. Factors Affecting Students' Performance

\begin{tabular}{|l|c|c|c|}
\hline & N & Mean & SD \\
\hline Issues outside the school & 52 & 7.20 & 7.06 \\
\hline Issues within the school & 52 & 6.31 & 2.10 \\
\hline Teachers & 52 & 5.60 & 2.66 \\
\hline Total & 52 & & \\
\hline
\end{tabular}

In Table 3 the differences between the students with low rate of absenteeism and those with high rate of absenteeism is statistically significant $(\mathrm{p}=0.00)$. On the average therefore, high rate of school absenteeism is a barrier to students learning and achievement.

Table 3. t-Test: School Achievement and the Effects of School Barriers to Learning

\begin{tabular}{|l|c|c|c|c|}
\hline School Attendance & Mean & SD & “'t” & (p) \\
\hline Low rate of absenteeism & 4.35 & 2.74 & 6.355 & 0.000 \\
\hline High rate of absenteeism & 6.62 & .66 & & \\
\hline
\end{tabular}

The findings of this study suggested that the academic performance was significantly affected by absenteeism.

Table 4. High School Performance of Students and Praiseworthiness

\begin{tabular}{|l|c|c|c|}
\hline & $\mathbf{N}$ & Mean & $\begin{array}{c}\text { Std. } \\
\text { Deviation }\end{array}$ \\
\hline Adaptation to the school culture helps my learning & 50 & 6.55 & 0.829 \\
\hline Teachers help my learning & 50 & 5.31 & 1.034 \\
\hline Family helps my learning & 50 & 3.32 & 1.846 \\
\hline Valid N (listwise) & 50 & & \\
\hline
\end{tabular}

Students who achieve high levels of performance at school are praised by their teachers with a high mean score $(M=6.55)$ as shown in Table 4. Much as these students have understood the cultural values of their new country and are well adapted to this culture, they also attend school regularly with a lower rate of absenteeism $(\mathrm{M}=4.35)$ as against low performance of students with a high rate of school absence $(M=6.62)$ as shown in Table 3. Many minority students who have managed very well in school praise themselves and the supportive school system other than family and social support issues. Many researches point to the view that the school performance of immigrants is directly correlated with their adaptation 
strategies to the school in particular and the new society at large (Alhassan \& Kuyini, 2012).

\section{Teachers' Responses}

Out of the 50 teachers who took part in the study $\mathrm{N}=40(80 \%)$ were ethnic Norwegians with Western cultural background and $\mathrm{N}=10(20 \%)$ were teachers of non-western cultural background. The majority of the teachers had experience teaching minority students and had some cross-cultural knowledge, while none of these teachers except $\mathrm{N}=1(2 \%)$ had migration pedagogy. The findings with more serious implications for teacher evaluation and moral judgement were the $98 \%$ of the teachers having no migration pedagogy education and majority of whom are from western background.

\section{Teachers' Cross-Cultural Knowledge}

Table 5. Teachers' Cross Cultural Knowledge and Moral Judgement

\begin{tabular}{|l|c|c|c|}
\hline Frequency & N & Percent & $\begin{array}{c}\text { Cumulative } \\
\text { Percentage }\end{array}$ \\
\hline Below Average Knowledge & 17 & 34.0 & 34.0 \\
\hline Good Knowledge & 21 & 42.0 & 66.0 \\
\hline Very Good Knowledge & 12 & 24.0 & 100.0 \\
\hline Total & 50 & 100.0 & \\
\hline
\end{tabular}

Table 5 shows that teachers in this study reported good levels of cultural knowledge of the minority students they are teaching. These teachers are likely to give a fair judgement of students' behaviour. Nevertheless, up to $34 \%$ of the teachers reported levels of cultural knowledge that is below average warranting a serious concern about whether these teachers could make any fair judgment about minority students` behaviour given their limited cross-cultural knowledge. It is obvious therefore; that teachers need cross-cultural courses and training to enable them understand the diverse students in the school.

Table 6. Students who Absent themselves from School should be Punished

\begin{tabular}{|l|c|c|}
\hline Response & Frequency & Percent \\
\hline No & 10 & 20 \\
\hline Yes & 40 & 80 \\
\hline Total & 50 & 100 \\
\hline
\end{tabular}

When the 50 teachers were asked whether absentee students should be punished or not $\mathrm{N}=40(80 \%)$ of the teachers answered, "yes" while $\mathrm{N}=10(20 \%)$ said "no" as shown in Table 6. Many students who found it fair also supported this view of punishment. Minority students who take part in introduction program are entitled to an introduction grant, and when they are absent from school they are punished in a form of money deductions from the grant they earn. Other students from various municipalities not registered under introduction program, when absent from school exceeding certain minimum number of days are punished in a 
form of no basis for assessment. For minority students registered under introduction program absenting themselves from school is punishable by law, making this punishment legal.

\section{Discussion}

This study sought to examine the concept of moral judgement of students by their teachers and the experiences of migrant students of their teachers' praiseworthiness or blameworthiness of school achievement in selected secondary schools in the Østfold District of Norway. Data was collected from 52 students and 50 teachers to answer the question of teachers and students morally blameworthy or praiseworthy for factors that are known to be beyond their control in terms of students' behavior and school performance.

The overall results showed that teachers approach to evaluation of moral blameworthiness or praiseworthiness of their students may not be acceptable due to teachers' limited cross-cultural knowledge of minority students. The praiseworthiness of students' high school achievement is rather a result of students' cultural adaptations strategies of the school and the society at large as opposed to factors outside the school environment. However, the blameworthiness of students' behaviour and their low school performance are results of factors that the students could not do anything about, and also beyond the understanding of their teachers. With students` truancy as correlated to their low school achievement may be attributed to social, mental or psychological issues, which these students are struggling with, the case of which needs to be addressed by school authorities.

The findings relating this study`s second question indicated that there are no universally accepted moral rules when teachers make moral judgments on their students. The trustworthiness and blameworthiness of minority students' good and bad behaviours are in most cases underpinned by good motives with the good intention of outwitting a particular problem, such as skipping school to attend driving courses to get a driver's license. Researchers have found that moral judgment is a biting philosophical phenomenon and teachers' moral judgment has little effect on students' performance (Edmunds \& Warburton, 2012).

McAlpine (2014) quoting Elliot "Most of the evil in this world is done by people with good intensions" could be related to minority students' actions and their teachers' (McAlpine, 2014, p. 34). This Quote, attributed to T.S. Elliot, illustrates very well the learning situations of minority students how clouded and difficult the topic of morality can be to judge their actions and performances. As society progresses and our understanding of the human psyche grow, this truth also seems to grow. Also, minority schoolwork is often interrupted by them taking up small jobs to support themselves and top up the little stipends that they get. Studies of subjects such as psychology and sociology have shown how susceptible to being influenced the human mind really is. So the question is raised: if minority students cannot control the influences of their mind, and teachers cannot control the influences of the diverse cultures of the students, society and otherwise general environment, which in turn shape thoughts and actions, how can they be held 
morally responsible for them? The idea that sometimes minority students are morally judged for things that they in reality have no control over is something that has become known in philosophy as moral luck (Nelkin, 2013). This newfound insight points to the issue that teacher's standard approach to evaluation of moral blameworthiness or praiseworthiness may no longer be acceptable. Therefore, this study has sought to address the question of whether it is ever the case that students or even teachers are held morally blameworthy or praiseworthy for factors that are known to be beyond their control. In doing so it is argued in this study that the issue of moral luck is not one of morality, but of epistemology.

To give a grounded answer to the main research question, its essential elements must be understood, starting with the notion of moral blameworthiness and praiseworthiness. It seems that in everyday conversation as it is the course of this study the teachers use the vocabulary of morality relatively freely in discussions of right and wrong and acceptable conduct in a given situation. Teachers accept without giving much thought to it that morality is something fundamental, that we can all generally agree upon, which is not necessarily the case. For instance, most people in western society nowadays agree that hurting children is "bad". However, proverb 13:24 in King James' bible states that the opposite is true: "He that spareth his rod hateth his son: but he that loveth him chasteneth him betimes" (Proverb 13:24, King James' Bible). So a problem arises; which moral judgment is to be believed? Depending on whom you ask, the answer will probably vary. Clearly, it is not the case that morality is something fundamental, but rather something highly subjective. As such, what exactly does it mean for someone to make a moral judgment of someone else, that is, to hold someone morally blameworthy or praiseworthy? According to Nagel a moral judgement is different from other kinds of judgment in that it is a judgement of the individual, not the actions, thoughts, consequences or circumstances of the individual, but the character or being of the individual (Nagel, 1979, p. 138). This statement will be taken to mean by implication that we attach the associations, be they positive or negative, of the event upon which the individual is being assessed to the person him- or herself. So to hold someone morally blameworthy for something is to mentally or emotionally attach negative associations to the individual of this someone. While there are other modes of moral assessment, this mode of moral assessment proposed by Nagel is arguably the only one that is relevant as it is a question of holding someone morally blameworthy or praiseworthy, which stipulates emphasis on the character of an individual, rather than whatever else might be tied to that individual.

Furthermore the question in investigation requires for the case to be that someone is held morally blameworthy or praiseworthy not only for factors beyond their control, but for factors that are known, by the one making the moral judgment, to be beyond their control. This criterion complicates the situation further by bringing into this investigation of moral judgement the concept of knowledge. Entire branches of philosophy exist that adhere to different interpretations of knowledge simply because it is such a multifaceted phenomenon of experience, thought and reality. Summarised theory of knowledge states that what we call knowledge are simply beliefs that we are justified in thinking are true 
through evaluation of the means by which we came upon the belief, often referred to as "ways of knowing". There are five of these that are generally accepted: Perception, introspection, memory, reason and testimony (Steup, 2005). So for something to be accepted as "known" it must be justified through one or more of these methods of attaining knowledge. However, the argument could be made, in the case where a moral judgment is being made despite knowledge of the fact that the event was ultimately beyond the subject's control, that for there to be moral judgment of the subject either as blameworthy or praiseworthy there must be knowledge contrary to the knowledge of the subject's lack of control. Otherwise, what would the judgment be based on? So in the case there must, logically, be conflicting bodies of knowledge about the situation in the person making the judgment. If this is the case, then can either body of knowledge be accepted as complete? And if not, can there exist cases in which someone is judged morally for cases "known" to be beyond their control? The answer to these problems is once again highly subjective and open to different interpretations of knowledge. Additionally, this dilemma of conflicting bodies of knowledge is also closely related to the matter of "competing intuitions" in judgments of situations where moral luck is involved, discussed by Fiery Cushman in his discussion of moral luck on philosophy bites. He takes the case further by referring to studies aimed at discovering how this intuitional "mismatch" arises. According to this study it seems that moral judgment of character is made most frequently by an evaluation of intention, which disregards consequences, and that where the discrepancy arises is when the evaluation of suitable punishment is included (Cushman, 2008). So depending on whether or not we choose to acknowledge choice of punishment or reward as moral judgment or whether or not we choose to accept the coexistence of conflicting bodies of knowledge as valid, cases can be made for either the truth or untruth of the situation in question.

With regards to considerations of the distinction between evaluation of punishment and moral judgment another salient distinction presents itself; the distinction between moral judgment and legal judgment. For minority students registered under introduction program absenting themselves from school is punishable by law, making this punishment legal.

While it is unavoidable that some moral judgment enters into legal judgment as a consequence of its natural foundation of moral judgments, there are some very important distinctions to be made. Firstly, legal law is set, the judgment is not based on a subjective perception of the case as with moral judgment, but rather on scientific evidence, that is, if there is irrefutable proof that someone is guilty of a violation of the law, which is non-subjective and ideally, impartial. There will be a consequence in accordance with the judicial specifics of the violated law, which is well articulated in the study of Gert (2011). Secondly, there is the correctional aspect of the law. A concept that has become increasingly prominent with time is that of restorative justice; the idea that the law is there not to punish people, but to "meet the victim's needs, and to ensure that the offender is fully aware of the damage they have caused to people and of their liability to repair that damage" (Johnston, 2011, p. 1). From these two points it follows that legal judgment is 
often removed from moral judgment and that as such there is little here also, to advocate the affirmative of the essay question.

On the other hand, there are those few cases where there might be inconclusive evidence or evidence to show that minority students who are blamed for not coping with school work are, for instance, not having it easy mentally and psychologically. In these cases, where judgment has to be made on inconclusive evidence, there might be the case that someone is blamed or in a worse case scenario convicted, legally, for factors that are known, at least to some degree, to be beyond their control. And although the judgment is legal, it is effectually, in spite of the lacking moral sentiment in the judgment, a condemnation of an individual, based on factors that are beyond that individual's control.

\section{Conclusions}

In conclusion this study did not find any standard acceptance of moral rules and judgment globally, with as much as $96 \%$ of students answering nonconventionality of moral rules and judgement. The most critical findings of this study was that teachers evaluations and moral judgement were basically based on western values as $98 \%$ of the teachers lacked training in migration pedagogy as majority of the teachers (80\%) were of western background. The prevailing moral judgement of teachers as found by this study is basically level 1 of Kohlberg's morality theory where fixed rules dictate judgement and its subsequent punishment or reward. However, registered introduction program minority students could be dominated in level 2 of Kohlberg's theory, where law enforces punishment for absentee students without good reason.

Hence if preservice teachers programs could foreground the contribution of moral judgement, then higher percentage of pre-service teachers will reach the postconventional morality level and thus can have a better understanding of moral judgement and are capable of influencing their students with regard to ethics and morals.

On the other hand, study results indicated that Kohlberg fourth stage (Upholding/enforcing norms and Laws) is dominant. Hence if preservice teachers programs could foreground the contribution of moral judgement, then higher percentage of pre-service teachers will reach the post-conventional morality level and thus can have a better understanding of moral judgement and are capable of influencing their students with regard to ethics and morals.

It seems that the question this study set out to answer is not one that is readily answered, as a result of dilemmas involved in moral judgment shown in this study that teachers may lack clear initial intuitions to arrive at a fair judgement. Along the scope of the research questions, several, layered complications arise. Including the subjectivity of morality, how one chooses to define morality and the constraints of the concept of knowledge, the latter of which seems to be the most problematic. It is argued in this study, that it is not ever the case that we hold someone morally blameworthy or praiseworthy for factors known to be outside their control, simply because of the non -acceptability of the conflicting bodies of knowledge that necessarily must exist for the affirmative of the given scenario to take place as sufficiently justified to be called knowledge. However, I think it is often the case 
that we hold people to be morally blameworthy or praiseworthy for factors that are beyond their control, because we do not fully comprehend their lack of control over their situation, which is still bad. So perhaps teachers should make it their responsibility to give more consideration to the subject of moral judgment's control over the factors on which they are morally assessing them. Especially in the above mentioned case of legal judgment. For while it is not exactly moral judgment, it resembles moral judgment in effect, and the consequences of these flawed judgments can greatly impact minority student's life in a way that is unfair and incompatible with our society's values and ideals.

Interestingly, the findings of this study indicate that the mean scores of teachers' praiseworthiness of minority students' school achievement were slightly higher than their blameworthiness of minority students' under-school achievement mostly blamed on students' absenteeism. However, a definite conclusion is not applicable as the study involves two different groups whose behaviours and actions and the effects of these might be influenced by other factors and variables. Therefore, further study of other factors and variables such as students' psychological, mental and social conditions including school workload and school culture that might impact on student's behaviour and school performance is highly recommended.

\section{References}

Alhassan, A. M., \& Kuyini, B. A. (2012). Minority Students' Perceptions of Schooling and Teachers Quality to Support their Learning in Norway. World Journal of Education, 2(2) 95-108.

Awad, E., D'Souza, S., Kim, R., Schulz, J., Henrich, J., \& Shariff, A. (2018). The Moral Machine Experiment. Nature, 563(7729), 59-64.

Bucciarelli, M., Khemlani, S., \& Johnson-Laird, P. N. (2008). The Psychology of Moral Reasoning: Judgment and Decision. Oxford: Oxford University Press.

Cohen, L., \& Manion, L. (1994). Research Methods in Education. $4^{\text {th }}$ Edition. London: Routledge.

Colby, A., \& Kohlberg, L. (1987). The Measurement of Moral Judgment: Theoretical Foundations and Research Validations. Volume 1. Cambridge, MA: Cambridge University Press.

Crain, W. C. (1985). Theories of Development. Upper Saddle River, NJ: Prentice-Hall. Indianapolis, IN: Hackett Publishing.

Cushman, F. (2008). Crime and Punishment: Distinguishing the Roles of Causal and Intentional Analyses in Moral Judgment. Cognition, 108(2), 353-380.

Cushman, F., \& Young, L. (2011). Patterns of Moral Judgment Derive from Non-Moral Psychological Representations. Cognitive Science, 35(6), 1052-1075.

Cushman, F., Young, L., \& Hauser, M. (2006). The Role of Con- Scious Reasoning and Intuition in Moral Judgment: Testing Three Principles of Harm. Psychological Science, 17(12), 1082-1089.

Cushman, F., Young, L., \& Greene, J. D. (2010). Multi-System Moral Psychology. In J. M. Doris, \& The Moral Psychology Research Group (eds.), The Moral Psychology Handbook (pp. 47-71). Oxford, England: Oxford University Press.

Edmunds, D., \& Warburton, N. (2012). Fiery Cushman on Moral Luck [Podcast]. Philosophy Bites. 6, June. Retrieved from: https://bit.ly/3rhdxoh. [Accessed 18 October 2014]. 
Gert, B. (2011). The Definition of Morality. In E. N. Zalta(ed.), The Stanford Encyclopedia of Philosophy. Fall 2012 Edition.

Gigerenzer, G. (2010). Moral Satisficing: Rethinking Moral Behavior as Bounded. Topics in Cognitive Science, 2(3), 528-554.

Haidt, J. (2001). The Emotional Dog and its Rational Tail: A Social Intuitionist Approach to Moral Judgment. Psychological Review, 108(4), 814-834.

Haidt, J. (2007). The New Synthesis in Moral Psychology. Science, 316(5827), 998-1002.

Haidt, J., \& Hersh, M. A. (2001). Sexual Morality: The Cultures and Reasons of Liberals and Conservatives. Journal of Applied Social Psychology, 31(1), 191-221.

Haidt, J., \& Joseph, C. (2007). The Moral Mind: How 5 Sets of Innate Moral Intuitions Guide the Development of Many Culture-Specific Virtues, and Perhaps Even Modules. In P. Carruthers, S. Laurence, \& S. Stich (eds.), The Innate Mind (Volume 3, pp. 367-391). New York: Oxford University Press.

Haidt, J., \& Kesebir, S. (2010). Morality. In S. Fiske, D. Gilbert, \& G. Lindzey (eds.), Handbook of Social Psychology ( ${ }^{\text {th }}$ Edition, pp. 797-832). Hoboken, NJ: Wiley.

Haidt, J., Koller, S. H., \& Dias, M. G. (1993). Affect, Culture, and Morality, or is it Wrong to Eat your Dog? Journal of Personality and Social Psychology, 65(4), 613-628. New York: Cambridge Universyt Press.

Harman, G., Mason, K., \& Sinnott-Armstrong, W. (2010). Moral Reasoning. In J. M. Doris, \& The Moral Psychology Research Group (eds.), The Moral Psychology Handbook (pp. 206-245). Oxford, England: Oxford University Press.

Hauser, M. (2006). Moral Minds: How Nature Designed our Universal Sense of Right and Wrong. New York: HarperCollins.

Johnston, G. (2011). Restorative Justice Ideas, Values, Debates. $2^{\text {nd }}$ Edition. London: Routledge.

Kohlberg, L. (1981). The Philosophy of Moral Development. San Francisco, CA: Harper.

Li, S., Zhang, J., Li, P., Wang, Y., \& Wang, Q. (2019). Influencing Factors of Driving Decision-Making under the Moral Dilemma. IEEE Access, 7(Jun), 104132-104142.

Luzuriaga, M., Heras, A., \& Kunze, O. (2019). Hurting Others vs. Hurting myself, a Dilemma for our Autonomous Vehicle. SSRN (Mar).

McAlpine, F. (2014). Happy Birthday, T.S. Elliot: 20 of his Most Life-Affirming Quotes. BBCAmerica. Retrieved from: https://bbc.in/3uSHtsX. [Accessed 13 October 2014].

Mikhail, J (2015). Universal Moral Grammar. In D. Edmonds, \& N. Warburton (eds.), Philosophy Bites Again (pp. 37-49). Oxford: Oxford University Press.

Nagel, T. (1979). Moral Questions. Cambridge University Press.

Nelkin, D. K. (2013). Moral Luck. In E. N. Zalta (ed.), The Stanford Encyclopedia of Philosophy. Winter 2013 Edition.

Nisreen M., \& Saleh M. (2019). Measuring Moral Judgment of Education Profession Ethics among Pre-Service Teachers of the School of Educational Sciences at the University of Jordan. International Education Studies, volume 12.

Paxton, J. M., \& Greene, J. D. (2010). Moral Reasoning: Hints and Allegations. Topics in Cognitive Science, 2(3), 511-527.

Rai, T. S., \& Fiske, A. P. (2011). Moral Psychology is Relationship Regulation: Moral Motives for Unity, Hierarchy, Equality, and Proportionality. Psychological Review, 118(1), 57-75.

Sripada, C. S., \& Stich, S. (2006). A Framework for the Psychology of Norms. In P. Carruthers, S. Laurence, \& S. Stich (eds.), The Innate Mind (volume 2, pp. 280-301). New York: Oxford University Press.

Steup, M. (2005). Epistemology. In E. N. Zalta (ed.), The Stanford Encyclopedia of Philosophy. Spring 2014 Edition. Oxford: Blackwell Publishing. 